Supporting Information:

\title{
Rhodium(I) Complexes of Tridentate $N$-Donor Ligands and Their Supramolecular Assembly Studies
}

Alan Kwun-Wa Chan, Di Wu, Keith Man-Chung Wong* ${ }^{* \dagger}$ and Vivian Wing-Wah Yam*

Institute of Molecular Functional Materials (Areas of Excellence Scheme, University Grants Committee, Hong Kong) and Department of Chemistry, The University of Hong Kong, Pokfulam Road, Hong Kong, P.R. China.

\footnotetext{
${ }^{\dagger}$ Current address: Department of Chemistry, South University of Science and Technology of China,
} No. 1088, Tangchang Boulevard, Nanshan District, Shenzhen, Guangdong, P.R. China. 


\section{Curve-Fitting with the Temperature-dependent Nucleation-elongation Model:}

For an isodesmic mechanism, ${ }^{[\mathrm{S} 1]}$ the normalized degree of aggregation (f) can be related to the temperature via a sigmoidal function (1), assuming a two-state equilibrium in which only short oligomers are present up to a high degree of aggregation.

$$
f(T)=\frac{1}{1+\exp \left[-0.908 \Delta H \frac{T-T_{m}}{R^{2}{ }^{2}}\right]}
$$

Under this assumption, the normalized degree of aggregation (f) of the complexes, which was deduced from the changes in the UV-vis absorption at different temperatures, are between 0 and 1 and where (f) $=0.5$ at $T=T_{m}$, which is the melting temperature, and $\mathrm{R}$ is the ideal gas constant. The enthalpy change $(\Delta \mathrm{H})$ of the aggregation process can therefore be deduced upon fitting the normalized degree of aggregation as a function of temperature.

\section{Curve-Fitting by NMR Dimerization Model in the Concentration-dependent}

\section{Process:}

For the NMR self-association model reported, ${ }^{[\mathrm{S} 2-\mathrm{S} 3]}$ it was assumed that in a monomer-dimer equilibrium system, two monomers (A) would associate to form a $\operatorname{dimer}\left(\mathrm{A}_{2}\right)$ as shown in equation (2):

$$
A+A \rightleftharpoons A_{2}
$$

The equilibrium constant of the association process $(\mathrm{K})$ can be expressed as equation (3) and the quantities $f_{m}$ and $f_{d}$ are mole fractions of A with $f_{m}+f_{d}=1$ :

$$
K=\frac{\left[A_{2}\right]}{[A]^{2}}=\frac{f_{d}}{2[A]_{0} f_{m}{ }^{2}}
$$


Meanwhile, the observed chemical shift $\left(\delta_{\text {obs }}\right)$ in the equilibrium can be expressed in terms of the intrinsic chemical shifts of monomer $\left(\delta_{\mathrm{M}}\right)$ and dimer $\left(\delta_{\mathrm{D}}\right)$ with respect to their mole fractions in equations (4), (5) and (6):

$$
\begin{gathered}
f_{m}=\frac{\delta_{d}-\delta_{o b s}}{\delta_{d}-\delta_{m}} \\
f_{d}=\frac{\delta_{o b s}-\delta_{m}}{\delta_{d}-\delta_{m}} \\
\delta_{o b s}=f_{m} \delta_{m}+f_{d} \delta_{d}=\frac{[A]}{[A]_{o}} \delta_{m}+\frac{2\left[A_{2}\right]}{[A]_{o}} \delta_{d}
\end{gathered}
$$

A quadratic equation (7) can then be obtained by substitution of the variables and terms in the equations (4), (5) and (6), to express $\delta_{\mathrm{obs}}$ in terms of $\delta_{\mathrm{m}}, \mathrm{K}$, and [A] and the association constant $\mathrm{K}$ can be determined by nonlinear least-squares fit using origin 8.0.

$$
\delta_{\mathrm{obs}}=\delta_{\mathrm{d}}-\left(\delta_{\mathrm{d}}-\delta_{\mathrm{m}}\right)\left\{\left(1+8 \mathrm{~K}\left[\mathrm{~A}_{\mathrm{o}}\right]\right)^{1 / 2}-1\right\} / 4 \mathrm{~K}\left[\mathrm{~A}_{\mathrm{o}}\right]
$$

\section{Determination of Dimerization and Trimerization Constants by Concentration- dependent UV-vis Absorption Studies:}

The NIR absorption bands that appear as the concentration of the complex increases are best interpreted in terms of an oligomerization of the rhodium complex cations: ${ }^{[\mathrm{S} 4]}$

$$
\begin{array}{r}
2 \mathrm{M} \stackrel{\mathrm{K}_{1}}{\rightleftharpoons} \mathrm{D} \\
\mathrm{D}+\mathrm{M} \stackrel{\mathrm{K}_{2}}{\rightleftharpoons} \mathrm{T}
\end{array}
$$

The equations (8) and (9) are the monomer-dimer and dimer-trimer equilibria respectively, where $\mathrm{M}=\left[\mathrm{Rh}\left(\mathrm{N}^{\wedge} \mathrm{N}^{\wedge} \mathrm{N}\right) \mathrm{CO}\right]^{+}, \mathrm{D}=\left\{\left[\mathrm{Rh}\left(\mathrm{N}^{\wedge} \mathrm{N}^{\wedge} \mathrm{N}\right) \mathrm{CO}\right]\right\}_{2}{ }^{2+}$, and $\mathrm{T}=$ 
$\left\{\left[\mathrm{Rh}\left(\mathrm{N}^{\wedge} \mathrm{N}^{\wedge} \mathrm{N}\right) \mathrm{CO}\right]\right\}_{3}^{3+}$. In the analysis of these equilibria, (8) and (9) have been utilized to give the mathematical expressions of (10) and (11):

$$
\begin{gathered}
\frac{[\mathrm{Rh}]}{\mathrm{A}_{2}{ }^{1 / 2}}=\frac{1}{\left(\varepsilon_{2} \mathrm{~K}_{1}\right)^{1 / 2}}+\frac{2 \mathrm{~A}_{2}{ }^{1 / 2}}{\varepsilon_{2}}+\frac{3 \mathrm{~K}_{2} \mathrm{~A}_{2}}{\varepsilon_{2}\left(\varepsilon_{2} \mathrm{~K}_{1}\right)^{1 / 2}} \\
\mathrm{~A}_{3}=\frac{\left(\varepsilon_{3} \mathrm{~K}_{2} \mathrm{~A}_{2}\right)^{3 / 2}}{\varepsilon_{2}\left(\varepsilon_{2} \mathrm{~K}_{1}\right)^{1 / 2}}
\end{gathered}
$$

where $[\mathrm{Rh}]$ is the total concentration of the rhodium(I) complexes, $\mathrm{A}_{2}$ and $\mathrm{A}_{3}$ are the absorbances due only to dimers and trimers respectively, and $\varepsilon_{2}$ and $\varepsilon_{3}$ are the corresponding molar extinction coefficients. By plotting $[\mathrm{Rh}] / \mathrm{A}_{2}{ }^{1 / 2}$ against the dimer absorbance $\mathrm{A}_{2}$ as a straight line in equation (10), from the slope $\left(2 / \varepsilon_{2}\right)$ and intercept $\left(1 /\left(\varepsilon_{2} \mathrm{~K}_{1}\right)^{1 / 2}\right.$, the corresponding molar extinction coefficients $\varepsilon_{2}$ and dimerization constant $\mathrm{K}_{1}$ can be determined. Similarly for equation (11), a plot of the trimer absorbance $A_{3}$ against $\left(\mathrm{A}_{2}\right)^{2 / 3}$ as a straight line, the slope $\left(\varepsilon_{3} \mathrm{~K}_{2}\right)^{1 / 2} / \varepsilon_{2}\left(\varepsilon_{2} \mathrm{~K}_{1}\right)^{1 / 2}$ can give the trimerization constant $\mathrm{K}_{2}$ ( $\varepsilon_{3}$ can be estimated as $\left.1.5 \varepsilon_{2}\right)$. 
Table S1a Crystal and Structure Determination Data of $\mathbf{1}$

$\begin{array}{ll}\text { empirical formula } & \mathrm{C}_{19} \mathrm{H}_{14} \mathrm{~F}_{3} \mathrm{SN}_{4} \mathrm{O}_{4} \mathrm{Rh} \\ \text { formula weight } & 554.31 \\ \text { temp, K } & 100 \\ \text { wavelength, } \AA & 0.85000 \\ \text { crystal system } & \text { Monoclinic } \\ \text { space group } & \mathrm{P} 21 / \mathrm{c} \\ \text { a, } \AA & 29.382(6) \\ \text { b, } \AA & 6.5740(13) \\ \text { c, } \AA & 22.388(4) \\ \alpha, \text { deg } & 90 \\ \beta, \text { deg } & 112.35(3) \\ \gamma, \text { deg } & 90 \\ \text { volume, } \AA^{3} & 3999.6(16) \\ Z, \AA^{3} & 8 \\ \text { density (calcd), g cm } & \\ \text { crystal size } & 1.841 \\ \text { index ranges } & 0.40 \mathrm{~mm} \times 0.30 \mathrm{~mm} \times 0.20 \mathrm{~mm} \\ & -31 \leq h \leq 28 \\ \text { reflections collected/unique } & -6 \leq k \leq 0 \\ \text { GoF on F } & 0 \leq l \leq 23 \\ \text { final R indices }[\mathrm{I}>2 \sigma(\mathrm{I})] & 4717 / 4717 \\ & 1.09 \\ & R_{1}=0.0851 \\ & 1.87 \text { and }-0.79 \\ & \end{array}$


Table S1b Selected bond lengths $[\AA]$ and angles $\left[{ }^{\circ}\right]$ for $\mathbf{1}$ with estimated standard deviations in parentheses

\begin{tabular}{llll}
\hline Rh1-N1 & $2.059(10)$ & $\mathrm{C} 16-\mathrm{O} 2$ & $1.172(15)$ \\
$\mathrm{Rh} 1-\mathrm{N} 2$ & $1.983(10)$ & $\mathrm{Rh} 1-\mathrm{Rh} 1^{\mathrm{i}}$ & $3.3489(18)$ \\
$\mathrm{Rh} 1-\mathrm{N} 3$ & $2.036(10)$ & $\mathrm{Rh} 1-\mathrm{Rh} 1^{\mathrm{ii}}$ & $3.3256(18)$ \\
$\mathrm{Rh} 2-\mathrm{N} 4$ & $2.052(10)$ & $\mathrm{Rh} 1-\mathrm{C} 16$ & $1.837(13)$ \\
$\mathrm{Rh} 2-\mathrm{N} 5$ & $1.982(10)$ & $\mathrm{C} 32-\mathrm{O} 1$ & $1.165(15)$ \\
$\mathrm{Rh} 2-\mathrm{N} 6$ & $2.050(1)$ & $\mathrm{Rh} 2-\mathrm{Rh} 2^{\mathrm{i}}$ & $3.3227(18)$ \\
$\mathrm{Rh} 2-\mathrm{C} 32$ & $1.840(13)$ & $\mathrm{Rh} 2-\mathrm{Rh} 2^{\mathrm{i}}$ & $3.3484(18)$ \\
& & & \\
$\mathrm{N} 2-\mathrm{Rh} 1-\mathrm{C} 16$ & $178.1(6)$ & $\mathrm{N} 1-\mathrm{Rh} 1-\mathrm{N} 2$ & $79.0(4)$ \\
$\mathrm{N} 3-\mathrm{Rh} 1-\mathrm{C} 16$ & $102.3(5)$ & $\mathrm{N} 1-\mathrm{Rh} 1-\mathrm{N} 3$ & $158.4(4)$ \\
$\mathrm{N} 1-\mathrm{Rh} 1-\mathrm{C} 16$ & $99.3(5)$ & $\mathrm{N} 2-\mathrm{Rh} 1-\mathrm{N} 3$ & $79.4(4)$ \\
$\mathrm{Rh} 1-\mathrm{Rh} 1-\mathrm{Rh} 1^{\mathrm{ii}}$ & $160.1(5)$ & $\mathrm{Rh} 1-\mathrm{C} 16-\mathrm{O} 2$ & $176.6(8)$ \\
$\mathrm{N} 4-\mathrm{Rh} 2-\mathrm{C} 32$ & $102.3(5)$ & $\mathrm{N} 4-\mathrm{Rh} 2-\mathrm{N} 5$ & $79.3(4)$ \\
$\mathrm{N} 5-\mathrm{Rh} 2-\mathrm{C} 32$ & $178.3(5)$ & $\mathrm{N} 4-\mathrm{Rh} 2-\mathrm{N} 6$ & $158.3(4)$ \\
$\mathrm{N} 6-\mathrm{Rh} 2-\mathrm{C} 32$ & $99.4(5)$ & $\mathrm{N} 5-\mathrm{Rh} 2-\mathrm{N} 6$ & $79.0(4)$ \\
$\mathrm{Rh2}$ & $\mathrm{Rh} 2-\mathrm{C} 32-\mathrm{O} 1$ & $175.1(13)$ \\
\hline
\end{tabular}




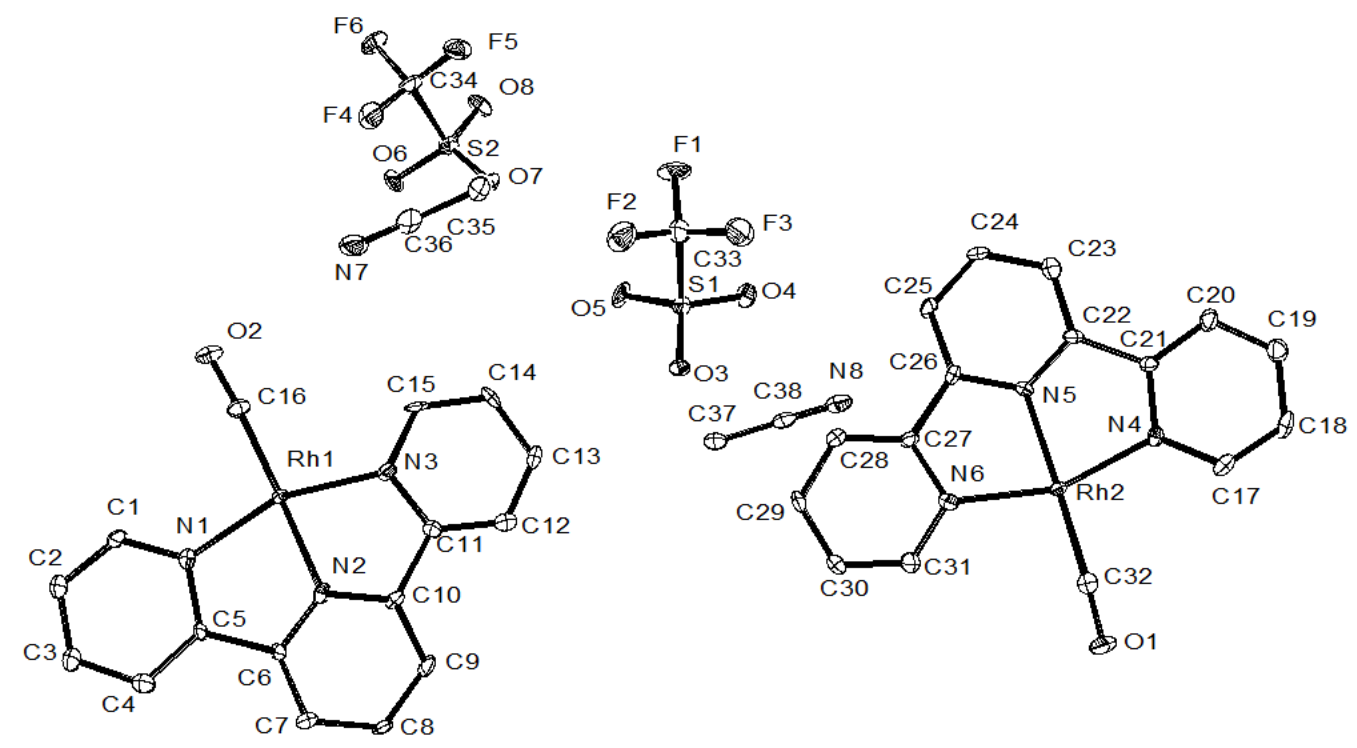

Figure S1 Perspective drawings of complex 1 with atomic numbering. Hydrogen atoms are omitted for clarity. Thermal ellipsoids were shown at the $30 \%$ probability level. 

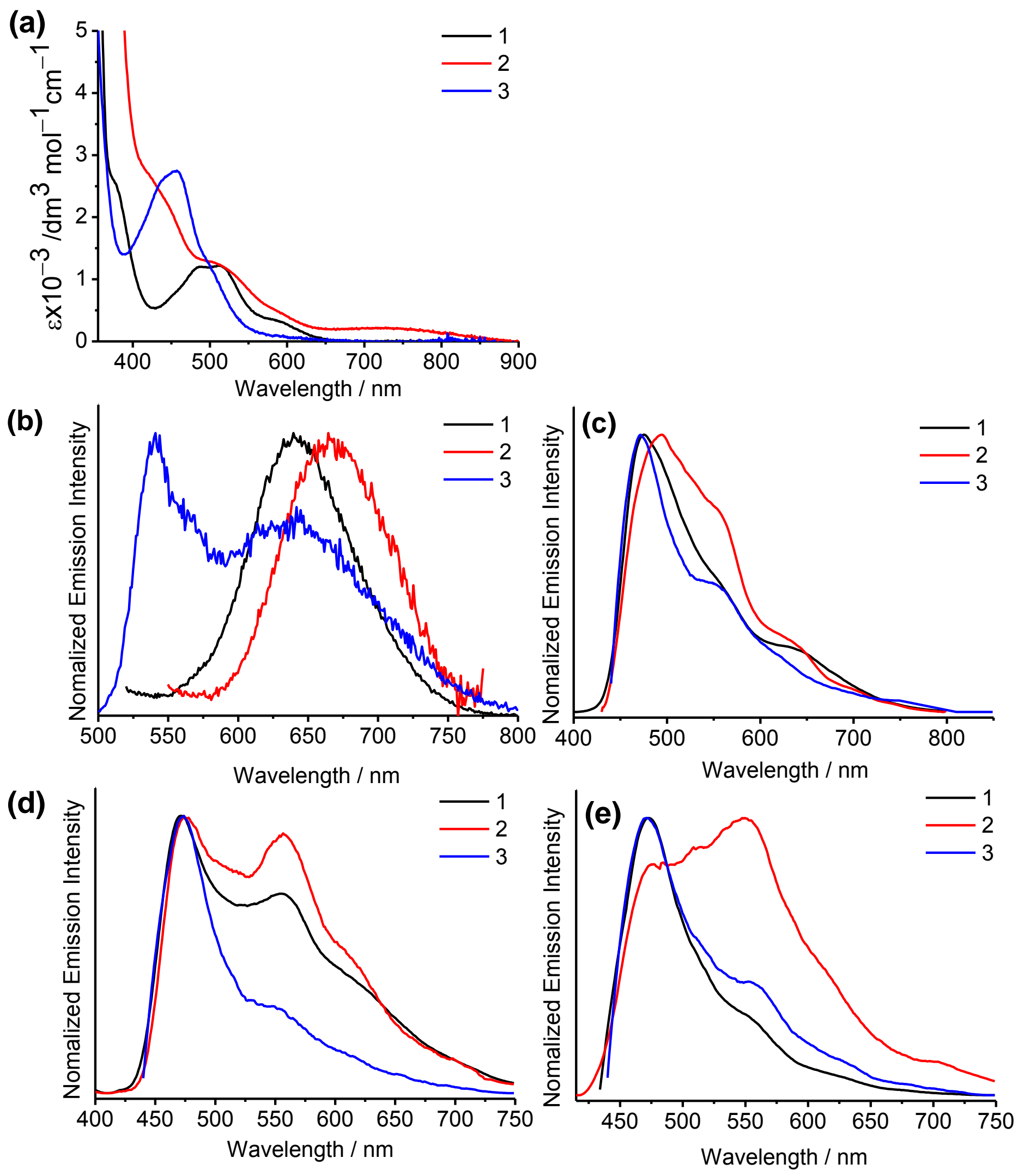

Figure S2 (a) UV-Vis spectra of $\mathbf{1}-\mathbf{3}$ in acetone at 298 K. (b) Normalized emission spectra of 1-3 in degassed acetone at $298 \mathrm{~K}$, (c) in butyronitrile glass at $77 \mathrm{~K}$, (d) in solid state at $298 \mathrm{~K}$ and (e) in solid state at $77 \mathrm{~K}$. 

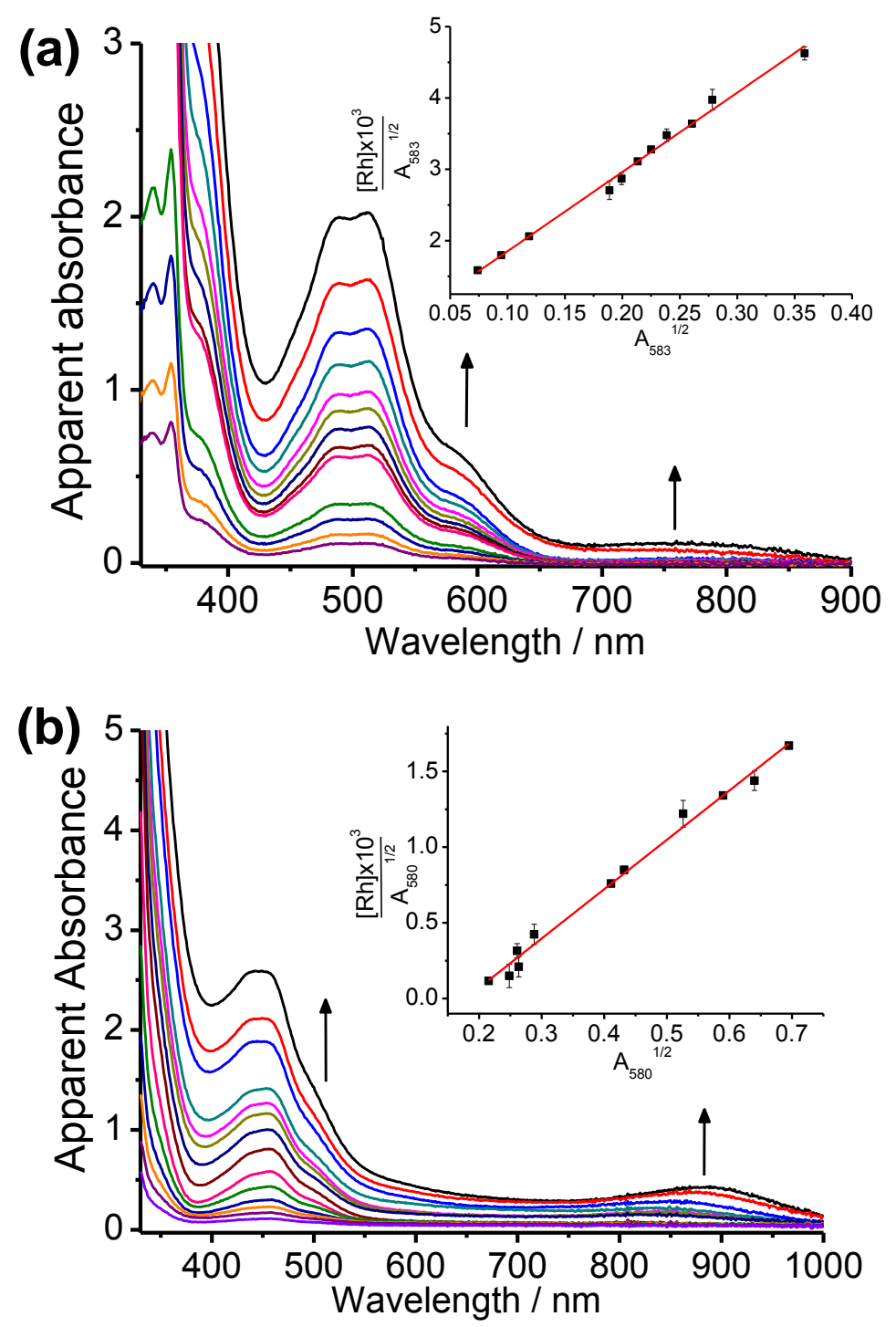

Figure S3 UV-Vis spectra of (a) 1 and (b) 3 from $2 \times 10^{-3}$ to $1 \times 10^{-5} \mathrm{M}$ in acetone at $298 \mathrm{~K}$. The apparent absorbance values have been obtained by correcting to $1-\mathrm{cm}$ path length equivalence. (Inset) Dimerization plot for monomer-dimer equilibrium. 
(a)

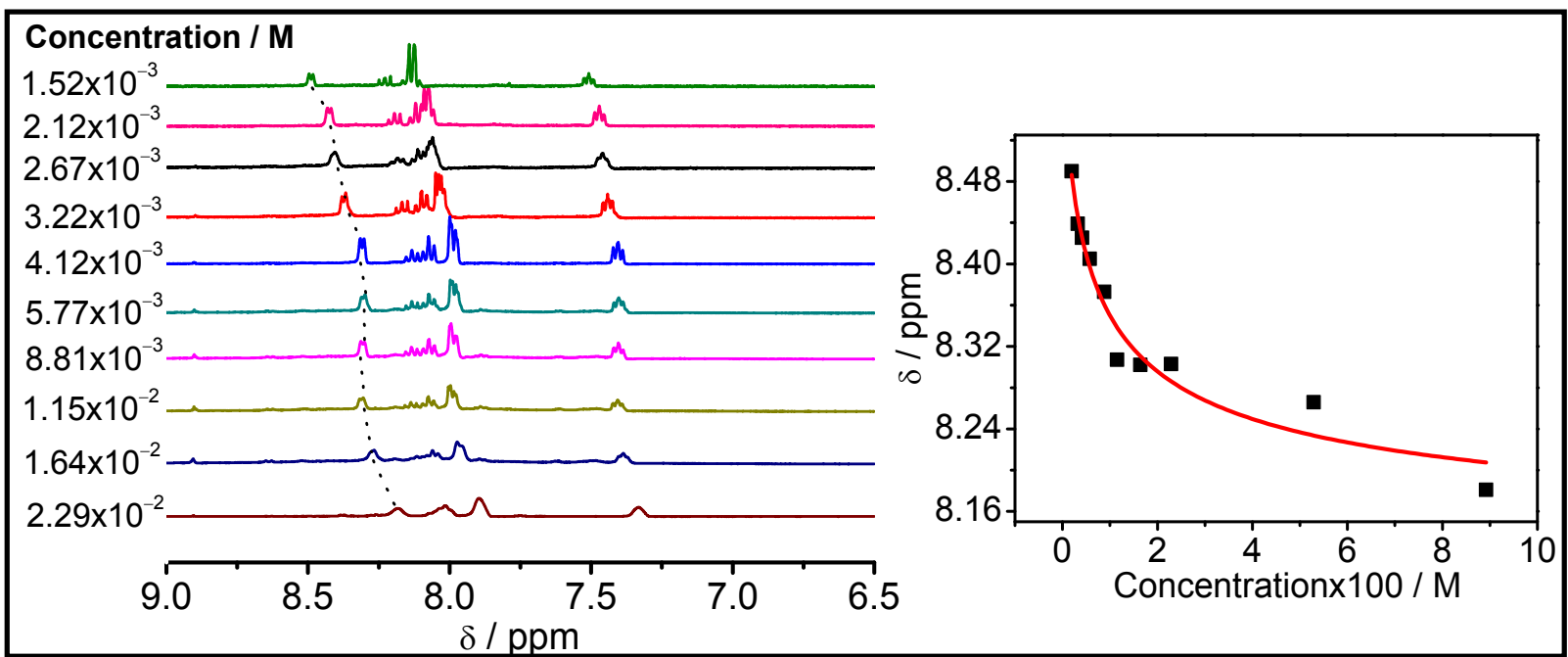

(b)

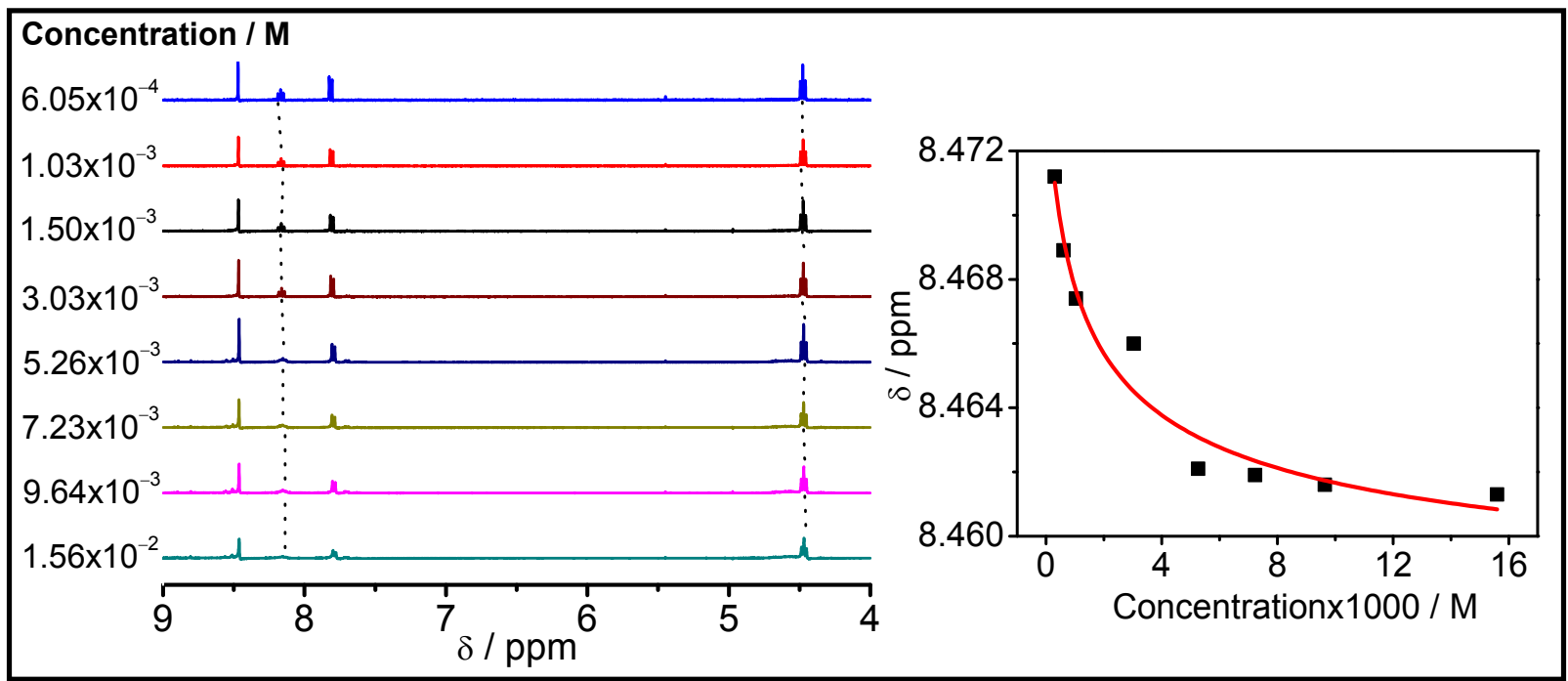

Figure S4 ${ }^{1} \mathrm{H}$ NMR spectra of (a) 1, (b) 3 upon increasing the concentration in $\mathrm{CD}_{3} \mathrm{CN}$ at 298 K; Insets: The corresponding plot of chemical shift against the concentration fitted with the self-association model of monomer-dimer equilibrium. 

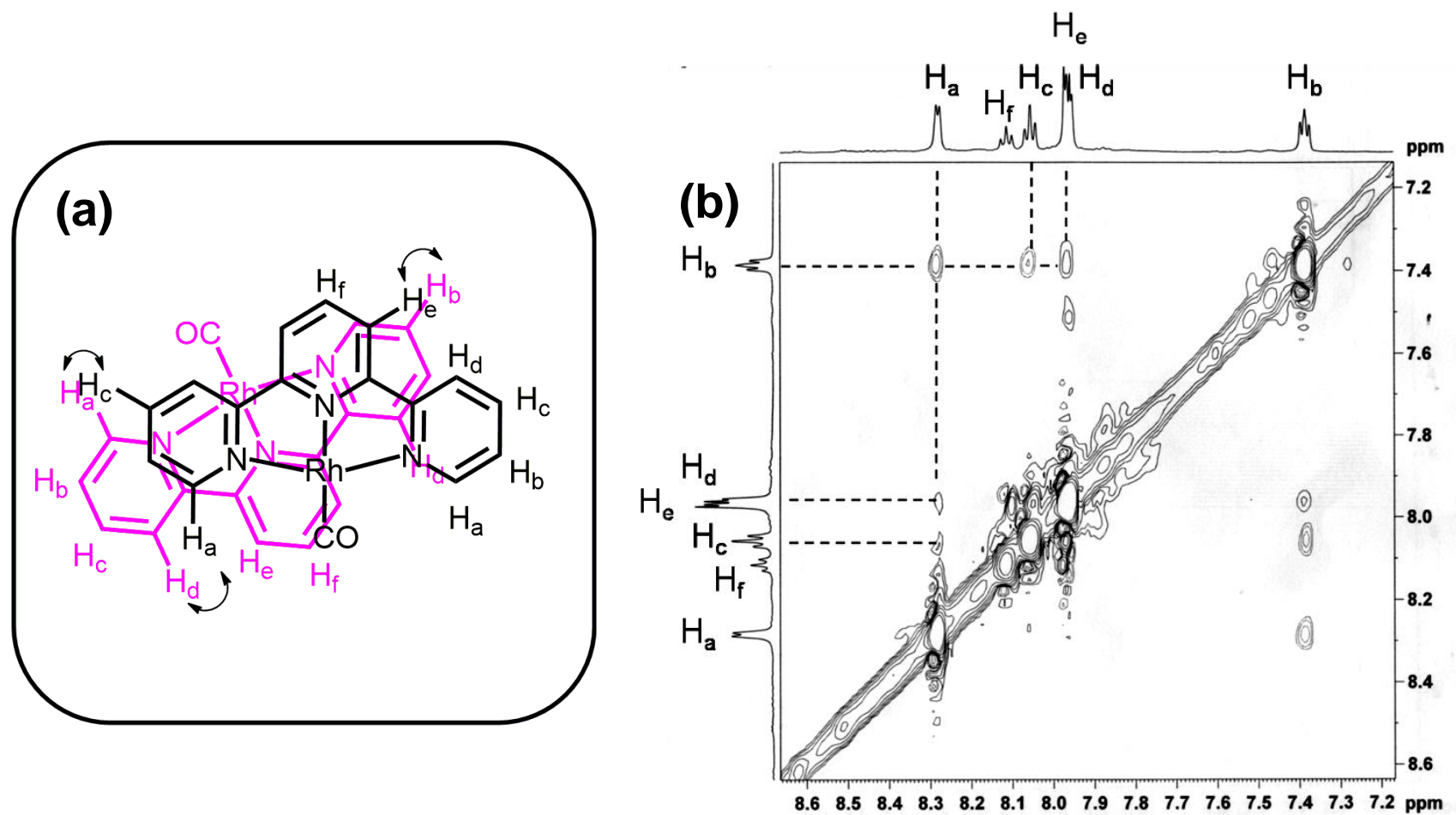

Figure S5 (a) Plausible association mode of 1 based on ${ }^{1} \mathrm{H}-{ }^{1} \mathrm{H}$ NOESY NMR experiment and (b) ${ }^{1} \mathrm{H}-{ }^{1} \mathrm{H}$ NOESY NMR spectrum of $1\left(5 \times 10^{-4} \mathrm{M}\right)$ in $\mathrm{CD}_{3} \mathrm{CN}$ at $298 \mathrm{~K}$ showing the aromatic region.
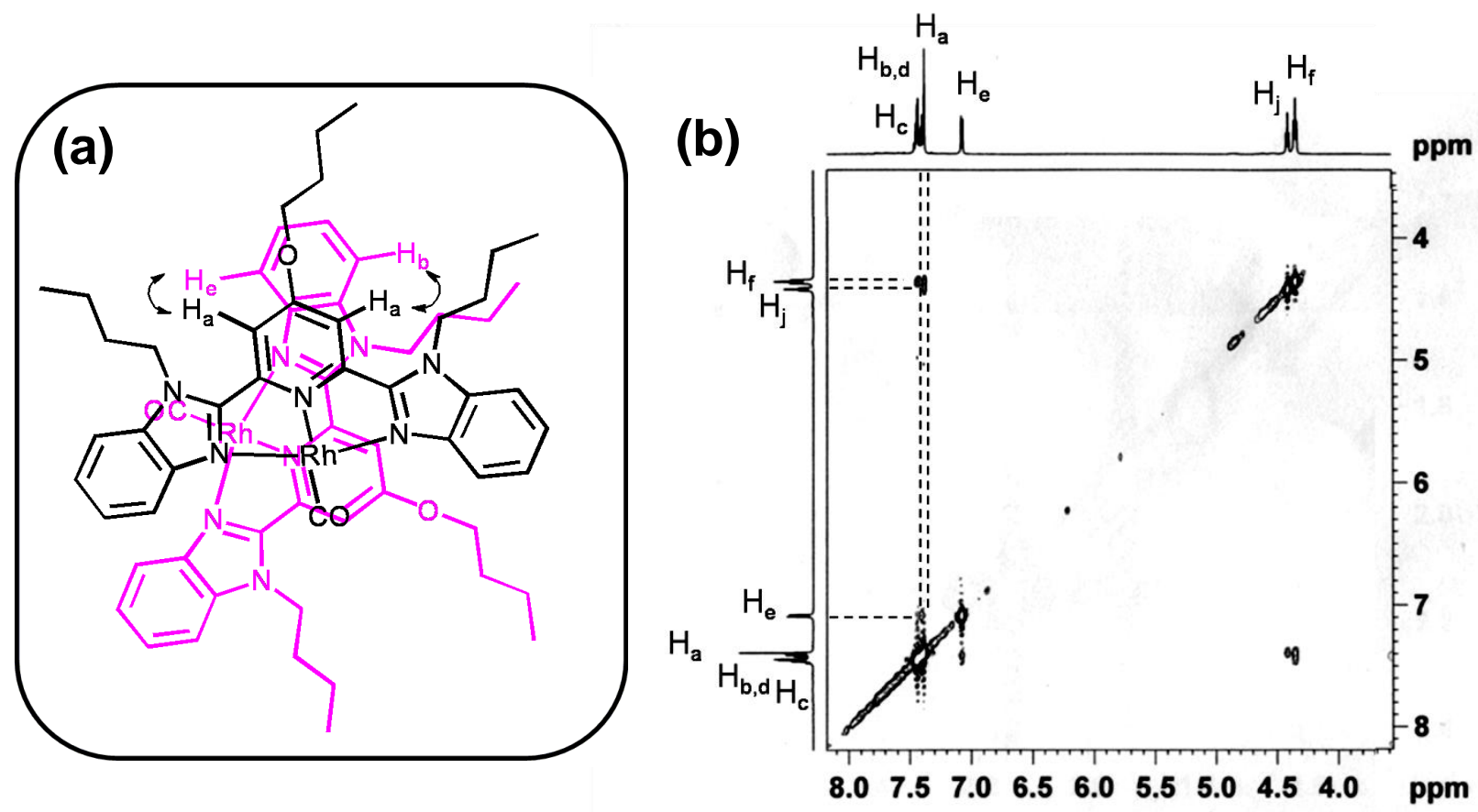

Figure S6 (a) Plausible association mode of 2 based on ${ }^{1} \mathrm{H}-{ }^{1} \mathrm{H}$ NOESY NMR experiment and (b) ${ }^{1} \mathrm{H}-{ }^{1} \mathrm{H}$ NOESY NMR spectrum of $2\left(6 \times 10^{-4} \mathrm{M}\right)$ in $\mathrm{CD}_{3} \mathrm{CN}$ at $298 \mathrm{~K}$ showing the aromatic region. 
(a)
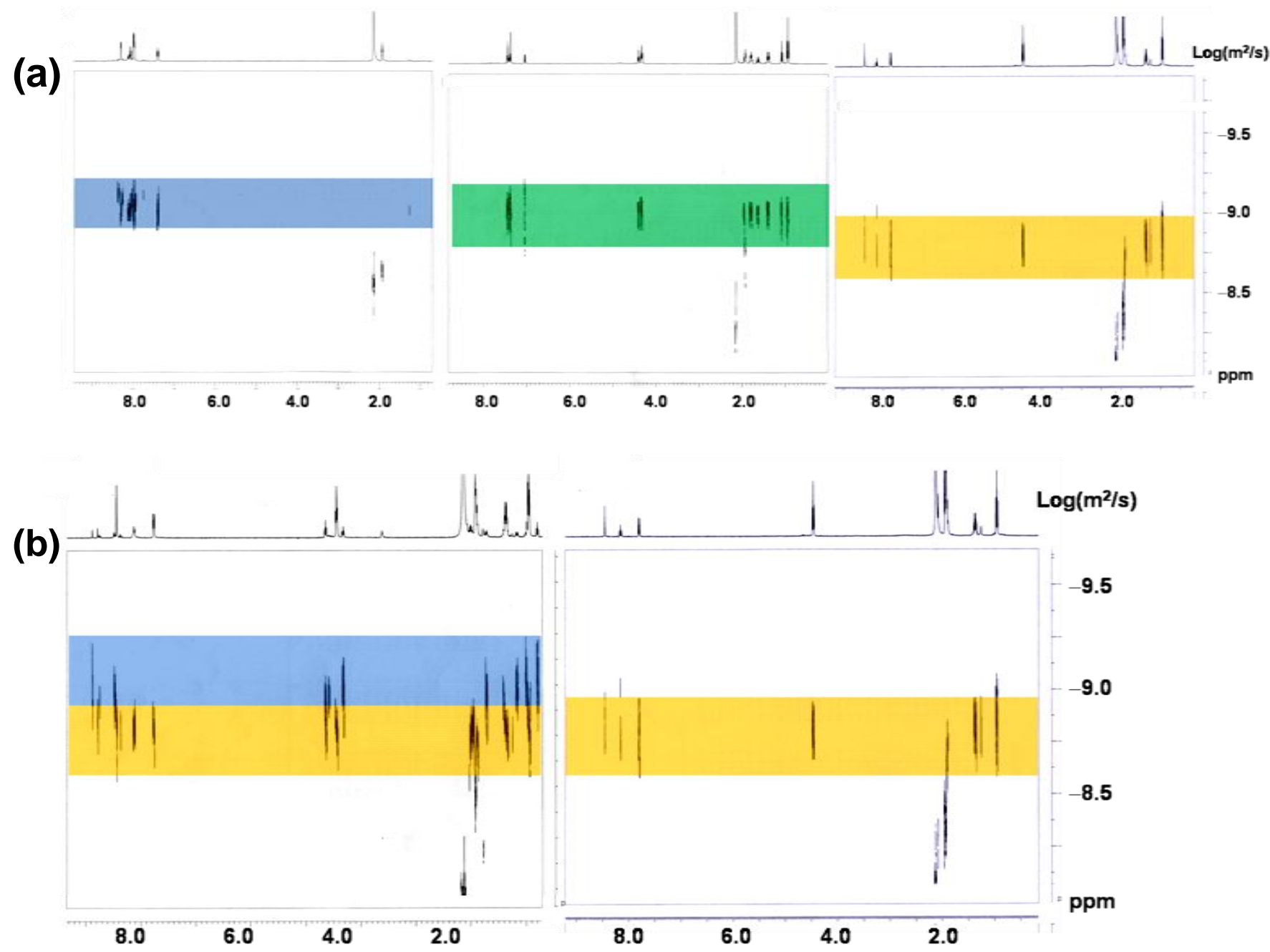

Figure S7 (a) DOSY NMR spectra of $\mathbf{1}$ (left), $\mathbf{2}$ (middle) and $\mathbf{3}$ (right) at a concentration of $8 \times 10^{-3} \mathrm{M}$; (b) DOSY NMR spectra of 3 at a concentration of $6 \times 10^{-2} \mathrm{M}$ (left) and $8 \times 10^{-3} \mathrm{M}$ (right) showing the growth of the signals of the oligomers. 

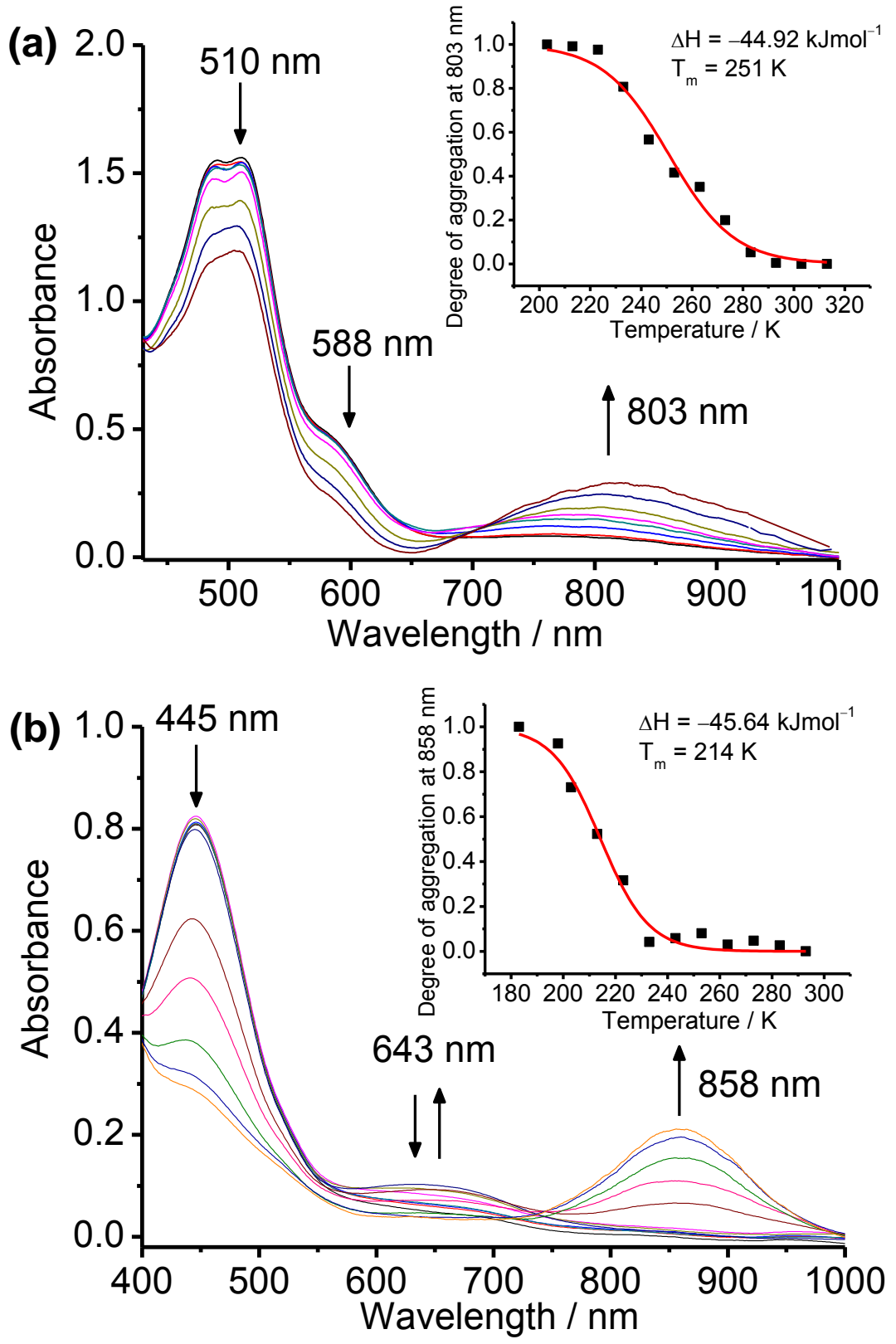

Figure S8 UV-Vis spectra of (a) 1 and (b) 3 in $4 \times 10^{-4} \mathrm{M}$ upon lowing the temperature in acetone. Insets: The corresponding sigmodal plot with monitoring of the absorption of trimers against temperature fitted with the isodesmic aggregation model. 

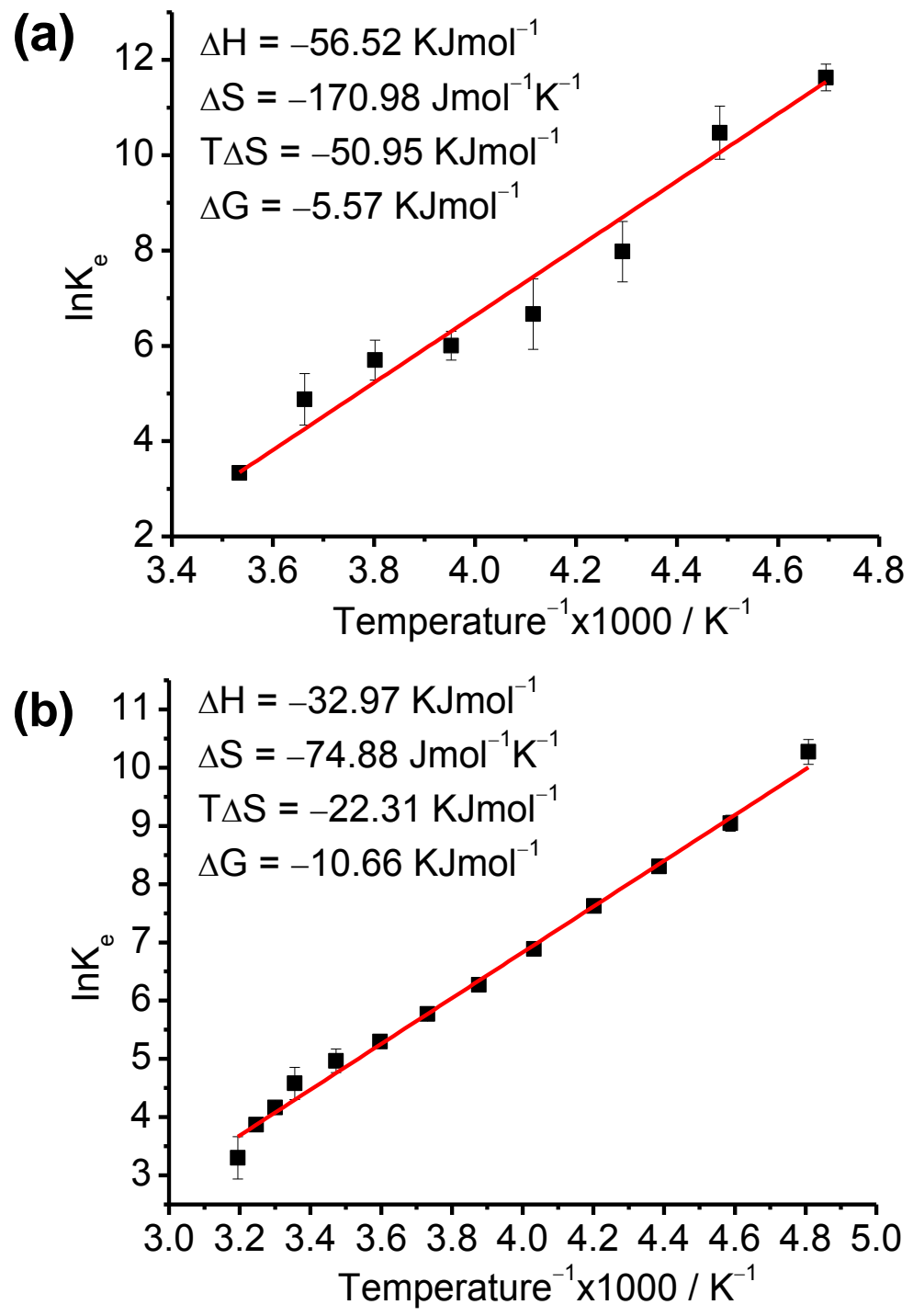

Figure S9 Van't Hoff plot of (a) 1 and (b) 2 with elongation equilibrium constant $K_{e}$ in dichloromethane at various temperatures with insets showing the thermodynamic data obtained. 


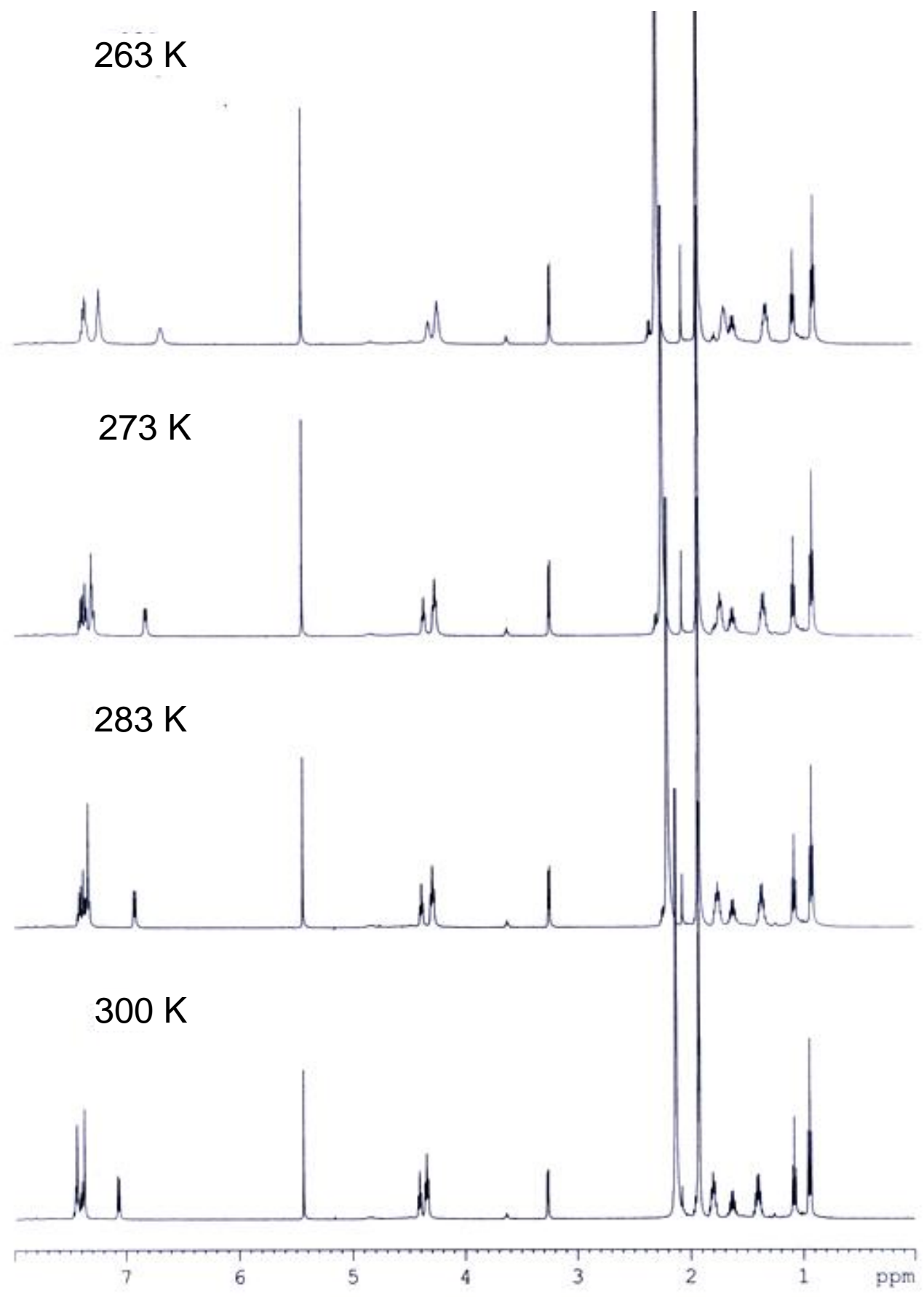

Figure S10 ${ }^{1} \mathrm{H}$ NMR spectra of 2 in $\mathrm{CD}_{3} \mathrm{CN}$ at $263 \mathrm{~K}, 273 \mathrm{~K}, 283 \mathrm{~K}$ and $300 \mathrm{~K}$. 

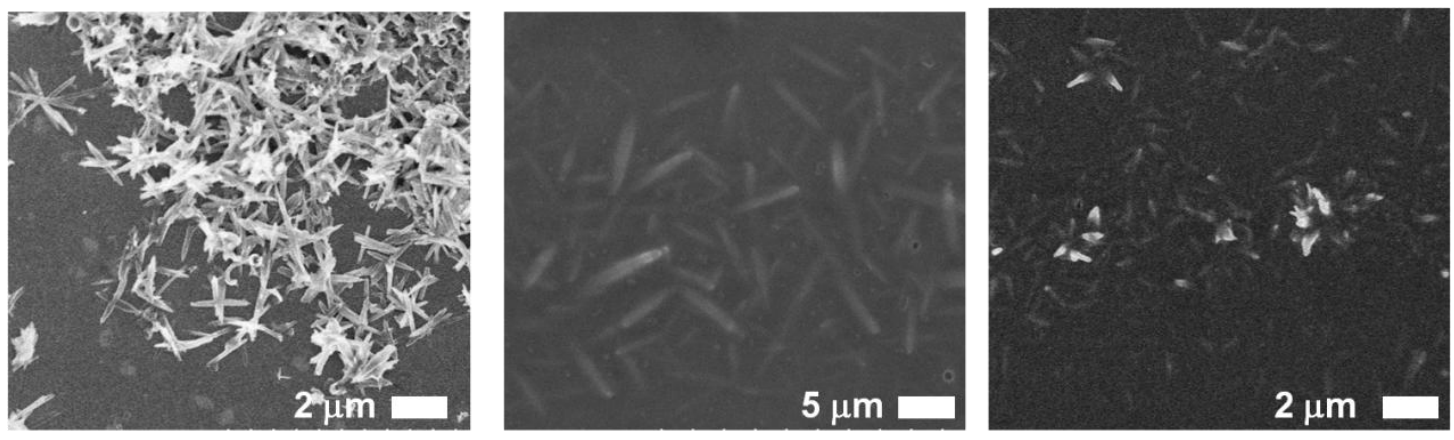

Figure S11 SEM images showing the wire-like nanostructures formation upon dispersion of $\mathbf{1}$ (left), $\mathbf{2}$ (middle) and $\mathbf{3}$ (right) in acetone solution. 


\section{References:}

[S1] M. M. J. Smulders, M. M. L. Nieuwenhuizen, T. F. A. de Greef, P. van der Schoot, A. P. H. J. Schenning, E. W. Meijer, Chem. Eur. J., 2010, 16, 362.

[S2] J.-S. Chen, R. B. Shirts, J. Phys. Chem., 1985, 89, 1643.

[S3] N. Saito, R. Terakawa, M. Yamaguchi, Chem. Eur. J., 2014, 20, 5601.

[S4] K. R. Mann, N. S. Lewis, R. M. Williams, H. B. Gray, J. G. Gordon, Inorg. Chem., 1978, 17, 828. 